九州大学学術情報リポジトリ

Kyushu University Institutional Repository

\title{
Relationship between Distributed Soil Moisture and Transpiration
}

Cho, Toshio

Laboratory of Irrigation and Water Utilization, Faculty of Agriculture, Kyushu University

Kuroda, Masaharu

Laboratory of Irrigation and Water Utilization, Faculty of Agriculture, Kyushu University

Tanaka, Akira

Laboratory of Irrigation and Water Utilization, Faculty of Agriculture, Kyushu University

$\mathrm{Ng}$, Ah Lek

Laboratory of Irrigation and Water Utilization, Faculty of Agriculture, Kyushu University

https://doi.org/10.5109/23866

出版情報: 九州大学大学院農学研究院紀要. 32 (1/2)，pp.41-59，1987-12. Kyushu University バージョン：

権利関係 : 


\title{
Relationship between Distributed Soil Moisture and Transpiration
}

\author{
Tosio Cho, M asaharu K uroda, Akira Tanaka, \\ and Ah Lek $\mathrm{Ng}$ \\ Laboratory of Irrigation and Water Utilization, Faculty of Agriculture, \\ Kyushu University 46-05, Hakozaki, Fukuoka 812
}

(Received June 12, 1987)

\begin{abstract}
Soil moisture distribution were examined under soil, crop and environmental factors. For soil factors, water retentivity index, hydraulic conductivity index and response index were defined. For crop factors root distribution and total root length per unit soil surface area, and for environmental factors daily transpiration and conductivity of lower layer were used. The simulation results showed that moisture distribution was large for 1) soil with small hydraulic conductivity index, 2) the state of root distribution under favorable moisture condition, 3) small total root length per unit soil surface area, 4) large daily transpiration, and 5) small conductivity of the lower layers.

Experiment on deep (distributed moisture condition) and shallow (homogeneous moisture condition) pots was conducted to study the relationship between soil moisture distribution and transpiration. To evaluate the distributed moisture condition the averaging methods by Taylor (1952), Gardner (1964), and Karamanos (1980) were used. Both the deep and shallow pot experiment showed that transpiration rate decreased with decreased in matric potential. Mean integrated potentials by the three methods were in good agreement with each other. The relationships between relative transpiration rate and mean integrated potentials of the deep pot experiment agreed fairly well with that of the shallow pot experiment. The results of the experiment showed that for a distributed moisture system the relationship between transpiration and soil moisture can be effectively evaluated by mean integrated values.
\end{abstract}

\section{INTRODUCTION}

Most irrigation problems are faced by the spatial and temporal distribution of moisture which often render the problems complicated. When irrigating the field the fact that moisture content at some depths, usually the surface layers, has reached a low value does not necessarily warrant immediate irrigation as other depths may still be at high moisture content which remains readily available for plant use. Soil moisture profile in the field seldom changes uniformly at any one time and the reference depth which can be used as a basis for initiating irrigation is difficult to obtain. Soil moisture distribution problem is also encountered when applying the works of plant science to irrigation.

Wadleigh (1946), Taylor (1952), Gardner (1964), Redmann (1976), and Karamanos (1980) have evaluated soil moisture distribution by the use of different weighting criteria to average observed soil moisture data, and they were mainly concerned with the relationship between plant responses such as yield, plant water potential, and averaged soil moisture.

The difficulties involved in evaluating soil moisture distribution arise mainly from 
the nonuniformity of root density and the variation in root resistance to water flow from the different layers of the root system (Taylor and Klepper, 1975).

In this paper, the focuses were on factors affecting soil moisture distribution, and on the relationship between distributed soil moisture status and transpiration. Factors which give rise to soil moisture distribution were grouped under soil, crop and environmental factors. For soil factors water retentivity index, hydraulic conductivity index and response index were defined. These indices were used as soil factors and were used to linearize the governing nonlinear partial differential equation of vertical flow in the calculation. For crop factors three root distributions and three total root lengths per unit soil surface area, and for environmental factors three daily transpirations and four conductivities of the soil layer below the root zone were assumed. These factors were used in the numerical model (Hillel et al., 1976) to simulate their effect on soil moisture distribution. The use of these factors to control soil moisture distribution was also examined.

Experiment on deep (distributed moisture condition) and shallow (homogeneous moisture condition) pots was conducted to study the relationship between distributed soil moisture status and transpiration. To evaluate the distributed moisture condition of the deep pot experiment, the averaging methods by Taylor (1952), Gardner (1964), and Karamanos (1980) were used to calculate a mean integrated potential. The mean integrated potentials of the three methods were compared with each other. The relationships between transpiration and mean integrated potentials of the deep pot experiment were compared with that of the shallow pot experiment.

\section{FACTORS AFFECTING SOIL MOISTURE DISTRIBUTION}

Soil moisture distribution over space and time could be attributed to three groups of factors : 1) Soil factors, e. g., soil moisture content, soil moisture retentivity and hydraulic conductivity, which affect soil water movement ; 2) Crop factors, e. g., root distribution and root extraction rate, which vary with space and time ; 3) Environmental factors, e.g., irrigation method, frequency and amount, rainfall, drainage, moisture condition of lower layers and depth of water table, which affect inputs to the root zone.

These three groups of factors, when act independently can bring about distribution. In nature they seldom act singly; instead they act concurrently and will result in a complicated system of soil water movement. In this paper, to understand better the effect of each group of factors, soil, crop and environmental factors were considered separately, i. e., when studying the effect of one group of factors, the other two groups were kept constant.

\section{Soil factors}

The state of soil moisture distribution is mainly caused by soil water movement. Soil moisture characteristics and hydraulic conductivity, which are functions of soil moisture content, are usually considered in describing soil moisture distribution. The governing non-linear partial differential equation of one-dimensional vertical flow is

$$
\frac{\partial \theta}{\partial t}=\frac{\partial}{\partial z}\left(k \frac{\partial \psi}{\partial z}+k\right)
$$


where $\theta$ is volumetric wetness, $\phi$ is matric potential, $k$ is hydraulic conductivity, $t$ is time, and $z$ is vertical ordinate taken positive upward.

Equation (1) is analytically cumbersome to treat. Linearization of (1) was introduced by defining three soil indices : water retentivity index $(\Theta)$, hydraulic conductivity index $(K)$, and response index $(Y)$. These indices were used as soil factors to examine their effect on soil moisture distribution.

Most crops function normally when soil moisture is in the range of $\mathrm{pF}$ values 2.0 to 3.0. And it is also the objective of irrigation to keep soil moisture within this range. Accordingly these indices were defined within this range :

Water retentivity index $=\Theta=\theta_{2}-\theta_{3}$

Hydraulic conductivity index $=K=\sqrt{\left(k_{2} \times k_{3}\right)}$

$$
\text { Response index }=K / \Theta=\frac{\sqrt{\left(k_{2} \times k_{3}\right)}}{\theta_{2}-\theta_{3}}
$$

in which $\Theta$ is water retentivity index, $K$ is hydraulic conductivity index, $\theta$ is volumetric wetness, and $k$ is hydraulic conductivity. Suffixes 2 and 3 are values at pF values 2.0 and 3.0, respectively.

The left-hand side of (1) can be expressed as

$$
\frac{\partial \theta}{\partial t}=\frac{d \theta}{d \phi} \cdot \frac{\partial \psi}{\partial t}
$$

The ordinary differential term on the right of (5) can be approximated as

$$
\frac{d \theta}{d \psi} \fallingdotseq \frac{\Delta \theta}{\Delta \psi}=\frac{\theta_{2}-\theta_{3}}{-100-(-1000)}=\frac{\Theta}{900}
$$

Assuming the approximation in (6) and taking $k$ to be $K$, (1) is reduced to

$$
\frac{\partial \psi}{\partial t}=\alpha^{2} \frac{\partial^{2} \psi}{\partial z^{2}}
$$

wherein $\alpha^{2}=900 \cdot K / \Theta$ is the diffusion coefficient of soil moisture.

These indices, besides providing a means to linearize the non-linear partial differential equation (1), also characterize soils in terms of water retentivity, hydraulic conductivity and response to water stress, and thus facilitate comparison of moisture distribution between soils with different physical properties.

Though in actual situation most of the soil moisture is depleted from the soil through root extraction and drainage, the phenomenon was simplified in the calculation by a model given in Fig. 1. In the model the water table is at a constant distance $l \mathrm{~cm}$ from the soil surface at which daily evapotranspiration $\left(E_{t}\right)$ was assumed to occur.

The soil moisture condition at time $t=0$ was assumed to be in equilibrium with the water table and is given below together with the boundary conditions :

Initial condition $\quad t=0, z \geqq 0, \psi=-z$ 


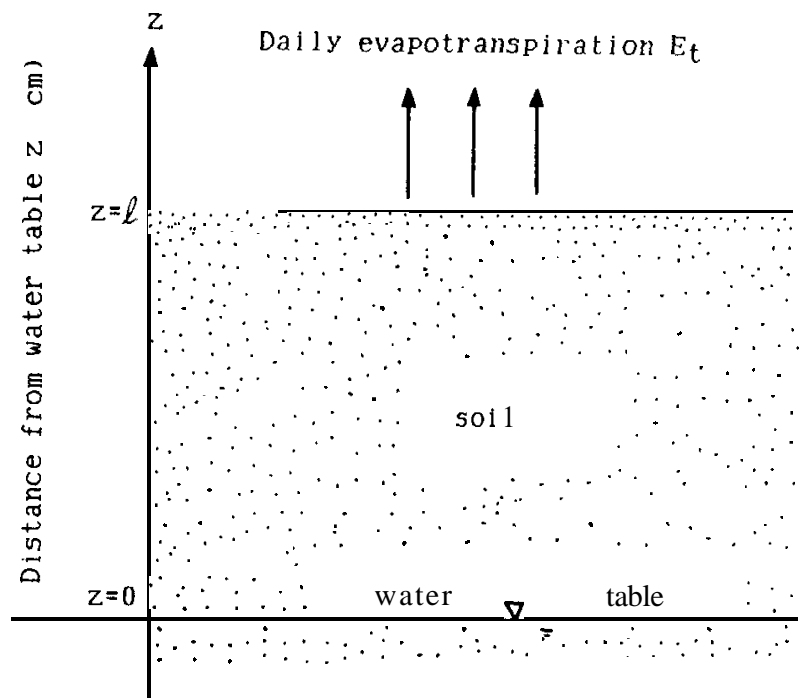

Fig. 1. One-dimensional model used to analyse soil moisture movement and distribution.

Boundary conditions $\quad t>0, \quad z=0, \quad \phi=0$

$$
z=l, \quad E_{t}=-K \frac{\partial \psi}{\partial z}-K
$$

Solving (7), an expression given by

$$
\psi=-\frac{E_{t} z}{K}-z+\frac{8 E_{t} l}{\pi^{2} K} \sum_{n=0}^{\infty}\left[\frac{(-1)^{n}}{(2 n+1)^{2}} \sin \frac{(2 n+1) \pi z}{2 l} \exp \left\{\frac{-(2 n+1)^{2} \pi^{2} \alpha^{2} t}{4 l^{2}}\right\}\right]
$$

is obtained.

At $t=\infty$, (8) gives

$\psi=\frac{-E_{t} z}{K}-z$

(9) shows that at $t=\infty \Theta$ has no effect on soil moisture distribution.

At $z=\mathrm{I}$, (8) gives

$$
\psi_{z=l}=\frac{-E_{t} l}{K}-l+\frac{8 E_{t} l}{\pi^{2} K} \sum_{n=0}^{\infty}\left[\frac{1}{(2 n+1)^{2}} \exp \left\{\frac{-(2 n+1)^{2} \pi^{2} \alpha^{2} t}{4 l^{2}}\right\}\right]
$$

Five types of soils with different $\Theta, K$ and $Y$ were used in the calculation (Table 1). Soil type N (loamy sand : sand, $88.6 \%$; silt, $10.3 \%$; clay, $1.1 \%$ ) was the soil used in the experiment (vid. experimental material and method). All other soil types were hypothetical soils chosen to have typical $\Theta, K$ and $r$ values to evaluate their effect on soil moisture distribution. These values were substituted into (8) or (10) to show how moisture of each soil change with time and depth under $E_{t}=5.0 \mathrm{~mm} / \mathrm{day}$. The results are given in Fig. 2 through 5. 
Table 1. Physical characteristics of soils used in soil moisture analysis: $\Theta$, Water retentivity index $: \mathrm{K}$, Hydraulic conductivity index $; \Upsilon^{*}$, Response index.

\begin{tabular}{cccc}
\hline Soil type & $\Theta\left(\mathrm{cm}^{3} / \mathrm{cm}^{3}\right)$ & $K(\mathrm{~cm} /$ day $)$ & $\gamma$ (cm/day) \\
\hline A & $\mathbf{0 . 2}$ & 0.1 & 0.5 \\
B & 0.1 & 0.1 & 1.0 \\
C & 0.1 & 0.01 & 0.1 \\
D & 0.2 & 0.01 & 0.05 \\
N & 0.068 & 0.031 & 0.46 \\
\hline
\end{tabular}

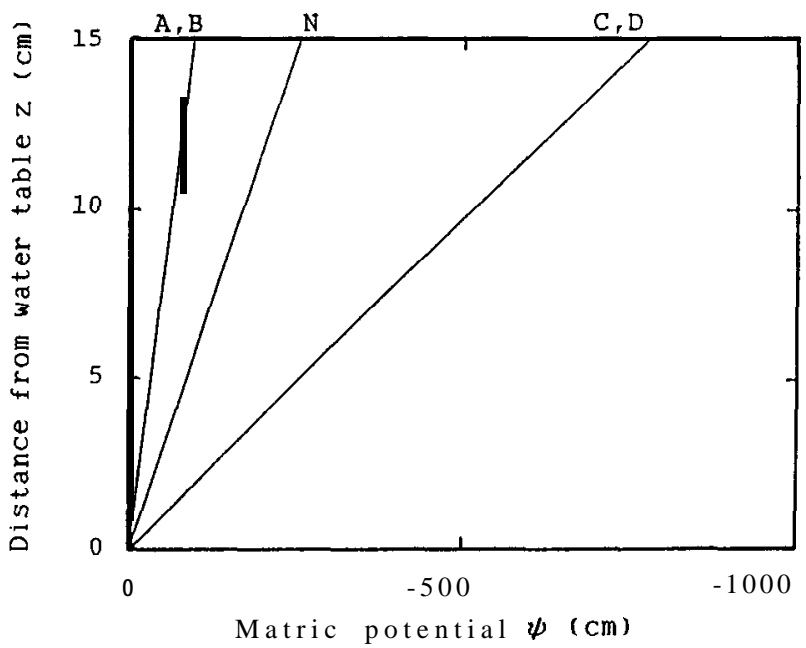

Fig. 2. Matric potential $\phi$ distribution at $\mathrm{t}=\infty$ for soil types of $\mathrm{A}, \mathrm{B}, \mathrm{C}, \mathrm{D}$ and $\mathrm{N}$ under daily evapotranspiration $E_{t}=5.0 \mathrm{~mm} /$ day.

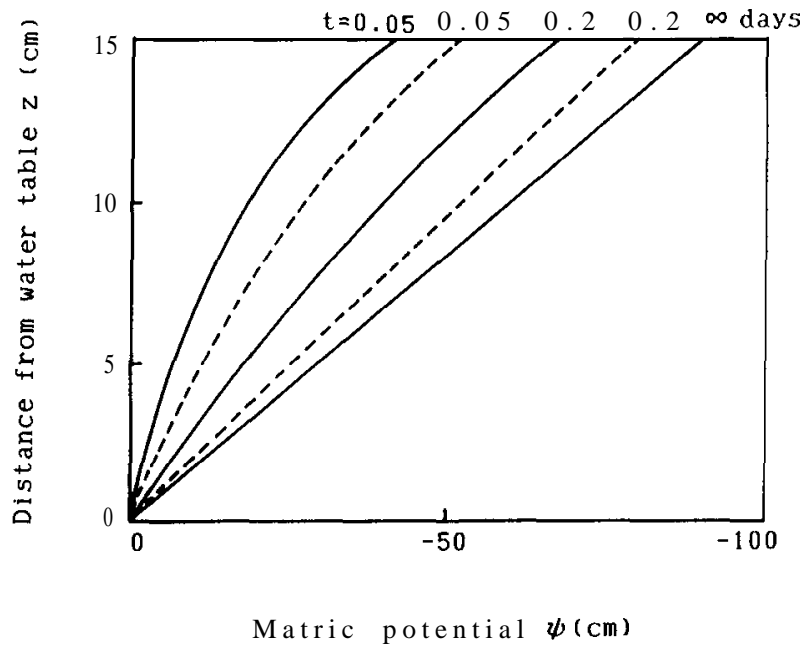

Fig. 3. Time course of matric potential $\phi$ for soil types of A (solid lines) and B (dashed lines) under daily evapotranspiration $E_{t}=5.0 \mathrm{~mm} /$ day. 


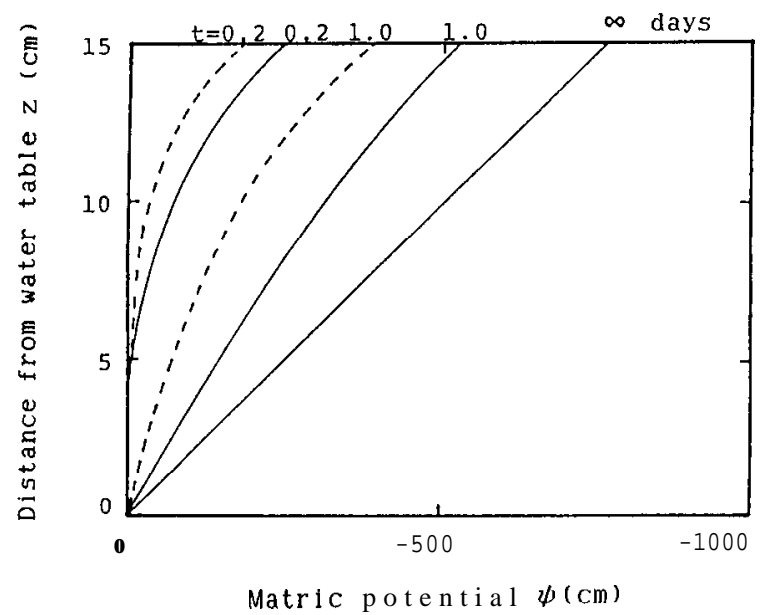

Fig. 4. Time course of matric potential $\phi$ for soil types of $\mathrm{C}$ (solid lines) and D (dashed lines) under daily evapotranspiration $E_{l}=5.0 \mathrm{~mm} /$ day.

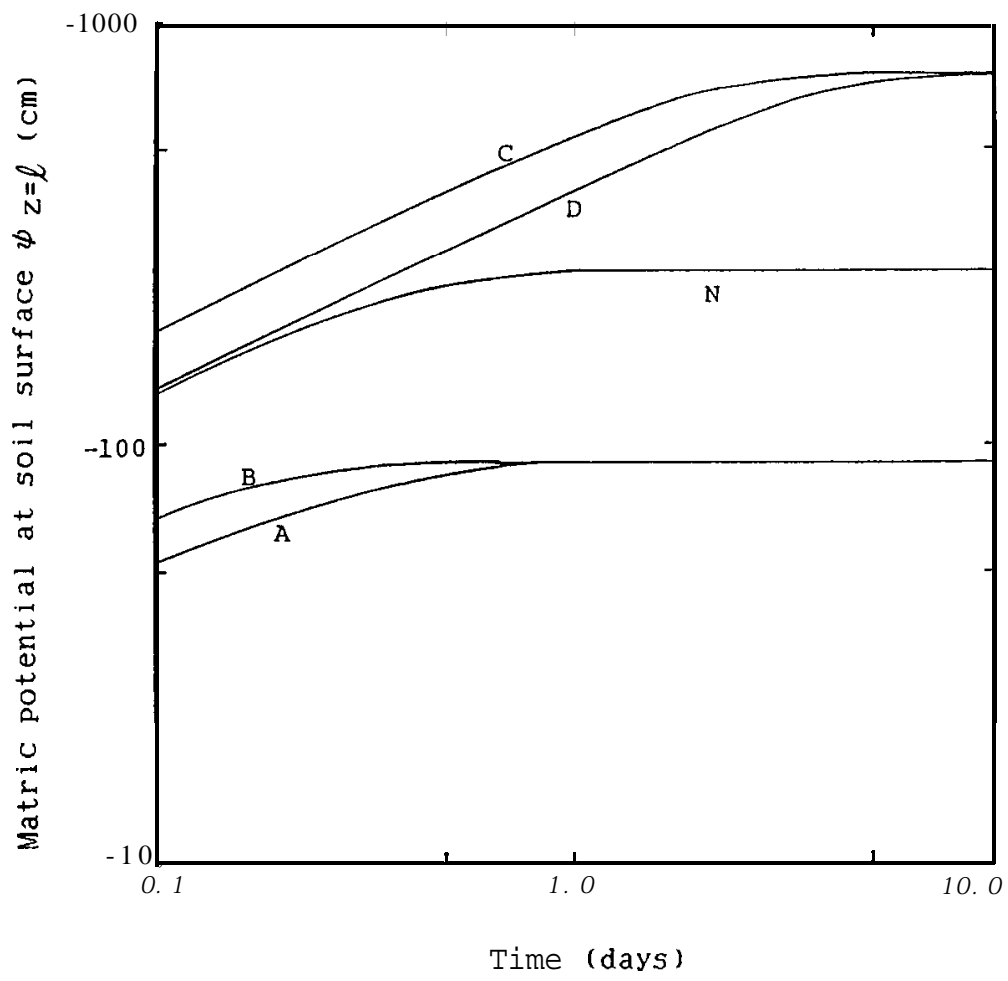

Fig. 5. Time course of matric potential at soil surface $\phi_{z=\imath}$ for soil types of A, B, C, $\mathrm{D}$ and $\mathrm{N}$ under daily evapotranspiration $E_{t}=5.0 \mathrm{~mm} /$ day and height from water table $l=15 \mathrm{~cm}$. 


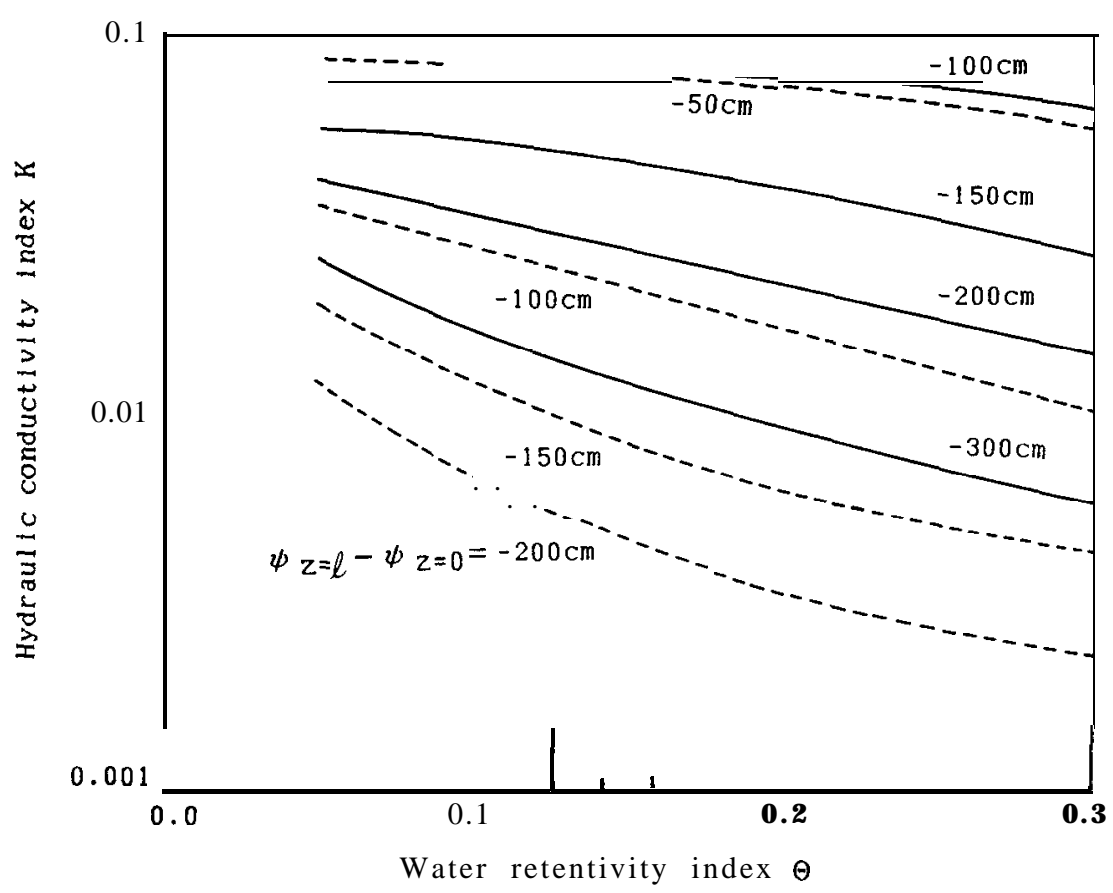

Fig. 6. Relationship between hydraulic conductivity index $K$ and water retentivity index $\Theta$ for matric potential difference at soil surface $z=1$ and that at $z=0 \phi_{z-1}-\phi_{z=0}$ under daily evapotranspiration $E_{t}=2.0 \mathrm{~mm} /$ day (dashed lines) and $E_{t}=5.0 \mathrm{~mm} /$ day (solid lines).

In Fig. 2 matric potential distribution at $t=\infty$ was in the order of soils A (B), N, and $\mathrm{C}(\mathrm{D})$, indicating that distribution was large for small $\mathrm{K} . K$ of the soils decreases in the same order. In Table 1 soils $\mathrm{A}$ and $\mathrm{B}$, or soils $\mathrm{C}$ and $\mathrm{D}$, show the same $K$ but different $\Theta$. The fact that soils $\mathrm{A}$ and $\mathrm{B}$, or soils $\mathrm{C}$ and $\mathrm{D}$, exhibit the same potential distribution indicates that $\Theta$ does not influence potential distribution at $t=\infty$, as evident from equation (9). Also, soils $\mathrm{A}$ and $\mathrm{D}$, or soils $\mathrm{B}$ and $\mathrm{C}$, show the same $\Theta$ but different $K$. The difference in potential distribution between soils $\mathrm{A}$ and $\mathrm{D}$, or that between soils $\mathrm{B}$ and $\mathrm{C}$, indicates that $K$ contributes greatly to potential distribution at $t=\infty$. Therefore, soil with large $K$ is necessary if distribution is to be kept small.

Over short period of time, distribution was relatively uniform for soils with the same $K$ but large $\Theta$. For example at $t=0.05$ day soil A when compared with soil B (Fig. 3), or at $t=0.2$ day soil D when compared with soil C (Fig. 4), showed a smaller distribution. Therefore, for short experimental time, soil with low $K$, such as soil D, can still be maintained relatively uniform.

In Fig. 5 the time required for the soils to attain a steady state was in the order of soils $\mathrm{B}, \mathrm{A}, \mathrm{N}, \mathrm{C}$ and $\mathrm{D}$. $Y$ of the soils decreases in the same order. At steady state surface potential is in the order of $\mathrm{A}$ (B), $\mathrm{N}$ and $\mathrm{C}$ (D). This shows that after attainment of steady state, i. e., after a long time has elapsed, soils with large $r$ can be kept relatively uniform. In this case, distribution with space is dependent on $K$ and 
selection of soil that will give a distribution within the allowable range is necessary, as evident in Fig. 1. In Table $1, \gamma$ of soil type $\mathrm{N}$ was comparable to that of soil $\mathrm{A}$, but since $K$ of soil type $\mathrm{N}$ was smaller, its distribution was observed to be larger at $t=\infty$.

Fig. 6 gives the relations between $K$ and $\Theta$ for different potential distribution range at $t=0.5$ day under $E_{t}=2.0$ and $5.0 \mathrm{~mm} /$ day. This figure can be used to select soil with a $\Theta$ and $K$ that will give the desired distribution range. For example, when matric potential in the vicinity of water table is $-200 \mathrm{~cm}$ and the allowable $\mathrm{pF}$ difference is 0.2 , soil surface matric potential has a value of $-317 \mathrm{~cm}$. For $E_{t}=5.0$ $\mathrm{mm} /$ day this can be achieved by selecting soil type above the -300 potential line.

\section{Crop and environmental factors.}

The numerical model by Hillel et al. (1976) was adapted to simulate the effect of crop and environmental factors (Table 2) on moisture distribution in soil type $\mathrm{N}$.

Table 2. Crop and environmental factors used in the simulation.

\begin{tabular}{cccc}
\hline & Crop Factors & Environmental & Factors \\
\hline $\begin{array}{c}\text { Root } \\
\text { distribution } \\
\text { type }\end{array}$ & $\begin{array}{c}\text { Total root length } \\
\text { per unit soil } \\
\text { surface area }(\mathrm{m})^{* *}\end{array}$ & $\begin{array}{c}\text { Daily } \\
\text { transpiration } \\
(\mathrm{mm} / \text { day })\end{array}$ & $\begin{array}{c}\text { Conductivity of } \\
\text { lower layer } \\
(\mathrm{cm} / \mathrm{s})\end{array}$ \\
\hline $\mathrm{RT}^{*}$ & $\mathrm{R} 1=6 \times 10^{2}$ & $\mathrm{~T} 1=9$ & $\mathrm{Cl}=1 \times 10^{-5}$ \\
$\mathrm{RC}$ & $\mathrm{R} 2^{*}=6 \times 10^{3}$ & $\mathrm{~T} 2^{*}=17$ & $\mathrm{C} 2=1 \times 10^{-6}$ \\
$\mathrm{RB}$ & $\mathrm{R} 3=6 \times 10^{\prime}$ & $\mathrm{T} 3=26$ & $\begin{array}{c}\mathrm{C} 3^{*}=1 \times 10-7 \\
\mathrm{c} 4=1 \times 10^{-8}\end{array}$ \\
\hline
\end{tabular}

* Representative values examined by different factors

* Total root length $(\mathrm{m})$ accumulated over depth per unit soil surface area $\left(\mathrm{m}^{2}\right)$

In the simulation, the soil column (I= $15 \mathrm{~cm})$ was divided into compartments of equal thickness of $1 \mathrm{~cm}$. Transpiration was assumed to be equal to total root extraction from the soil. Root extraction from each compartment was proportional to root length of each compartment. Matric potential below the root zone was assumed to be a constant value of $-50 \mathrm{~cm}$, and soil surface evaporation was zero. The initial moisture condition was in equilibrium with the layer below root zone. The vertical transient flow equation of the compartments is

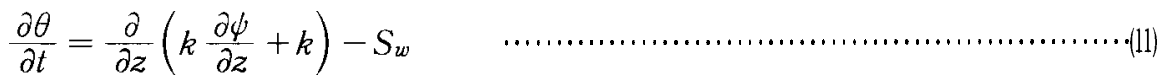

$$
\begin{aligned}
& S_{w}=\chi \mathrm{Rn}
\end{aligned}
$$

in which $S_{w}$ is a sink term representing root extraction, $x$ is a coefficient to convert root extraction from root length and is proportional to root distribution, and $\mathrm{Rn}$ is total root length per unit soil surface area.

Crop extracts water from soil in response to its transpirative needs with a distributed root system. In the simulation, three hypothetical root distributions (Fig. 7) $\mathrm{RT}^{*}$, most of the root in the upper $3 \mathrm{~cm} ; \mathrm{RC}$, uniform root distribution ; and $\mathrm{RB}$, most of the root in the lower $3 \mathrm{~cm}$, were used. Under $\mathrm{T}^{*}=17 \mathrm{~mm} / \mathrm{day}, \mathrm{R} 2 *=6 \times 10^{3}$ 


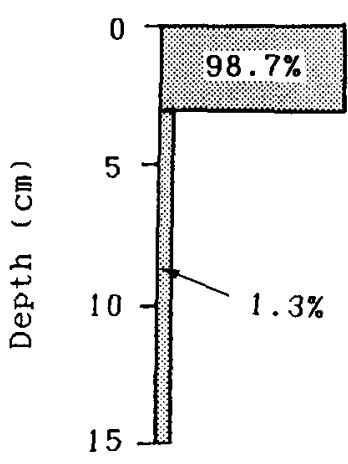

Case $\mathrm{RT}^{*}$

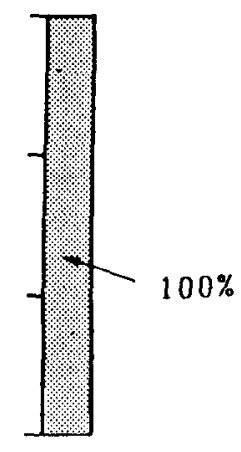

Case RC

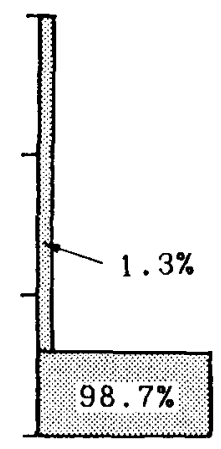

Case RB

\section{Relative root distribution (percent)}

Fig. 7. Illustration of three types of root distribution used for simulation $: \mathrm{RT}^{*}$, most of the roots distributed in the upper $3 \mathrm{~cm}$ of the root zone ; RC, uniform root distribution; $\mathrm{RB}$, most of the roots distributed in the lower $3 \mathrm{~cm}$ of the root zone.

$\mathrm{m} / \mathrm{m}^{2}$ and $\mathrm{C}^{*}=1 \times 10^{-7} \mathrm{~cm} / \mathrm{s}, \mathrm{RT}^{*}$ showed the largest distribution, and was followed by $\mathrm{RC}$ and $\mathrm{RB}$ (Fig. 8) at $t=24 \mathrm{hr}$. This indicates that distribution is large when root is distributed in the surface layers.

Simulation was also conducted to show how total root length in unit soil surface area affects soil moisture distribution. In field work the most useful parameter of root quantity is usually the total root length per unit soil surface area. The lengths vary quite widely, within limits of about $1 \times 10^{3} \sim 1 \times 10^{5} \mathrm{~m} / \mathrm{m}^{2}$ (Nye and Tinker, 1977). Three reasonable values of total root lengths per unit soil surface area, $\mathrm{R} 1=6 \times 10^{2}$, $\mathrm{R}^{*}=6 \times 10^{3}$ and $\mathrm{R} 3=6 \times 10^{4} \mathrm{~m}$ were assumed. Under $\mathrm{T} 2^{*}=17 \mathrm{~mm} / \mathrm{day}, \mathrm{C} 2=1 \times 10^{-6}$ $\mathrm{cm} / \mathrm{s}$ and root distribution $\mathrm{RT}^{*}$, the upper layers of $\mathrm{R} 1$ showed the largest distribution, and was followed by $\mathrm{R}^{*}$ and R3 (Fig. 9). Therefore, distribution is large for small root length per unit soil surface area.

In nature crops have a distributed root system with most of the roots in the surface layers when soil moisture conditions are favorable. It can be said that the way which crop root system is distributed in nature contributes greatly to soil moisture distribution.

The supply and demand concept was used to demonstrate the effect of environmental factors. Daily transpiration and a soil layer of low conductivity below the root zone were used to represent the demand and supply function, respectively. Three different daily transpirations, $\mathrm{T} 1=9, \mathrm{~T}^{*}=17, \mathrm{~T} 3=26 \mathrm{~mm} /$ day, and four conductivities $\mathrm{Cl}=1 \mathrm{X}$ $10^{-5}, \mathrm{C} 2=1 \times 10^{-6}, \mathrm{C} 3^{*}=1 \times 10^{-7}$ and $\mathrm{C} 4=1 \times 10^{-8} \mathrm{~cm} / \mathrm{s}$ were assumed.

Under $\mathrm{C}^{*}=1 \times 10^{-7} \mathrm{~cm} / \mathrm{s}, \mathrm{R} 2^{*}=6 \times 10^{3} \mathrm{~m} / \mathrm{m}^{2}$ and root distribution $\mathrm{RT}^{*}, \mathrm{~T} 3$ showed the largest distribution when compared with $\mathrm{T}^{*}$ and $\mathrm{T} 1$ at $t=24 \mathrm{hr}$ (Fig. 10). Soil moisture in the upper 3 layers in all curves varied greatly while that in the middle layers differed only slightly, as was obvious from the way root was taken to be 
distributed. Therefore, large daily transpiration will result in large soil moisture distribution.

Under $\mathrm{T}^{*}=17 \mathrm{~mm} /$ day, $\mathrm{R}^{*}=6 \mathrm{X} 10^{3} \mathrm{~m} / \mathrm{m}^{2}$ and root distribution RT* (Fig. 11), $\mathrm{Cl}$ and $\mathrm{C} 2$ were smoother than $\mathrm{C}^{*}$ and $\mathrm{C} 4$, and the distribution was in the order of $\mathrm{C} 4$, $\mathrm{C} 3{ }^{*}, \mathrm{C} 2$ and $\mathrm{Cl}$ at $t=24 \mathrm{hr}$. When soil water is lost to the atmosphere through root extraction, water below the root zone moves in to replace it if the conductivity of the lower layers were sufficiently large. Therefore, the conductivity of the lower layers contributes to the temporal but not the spatial distribution of soil moisture.

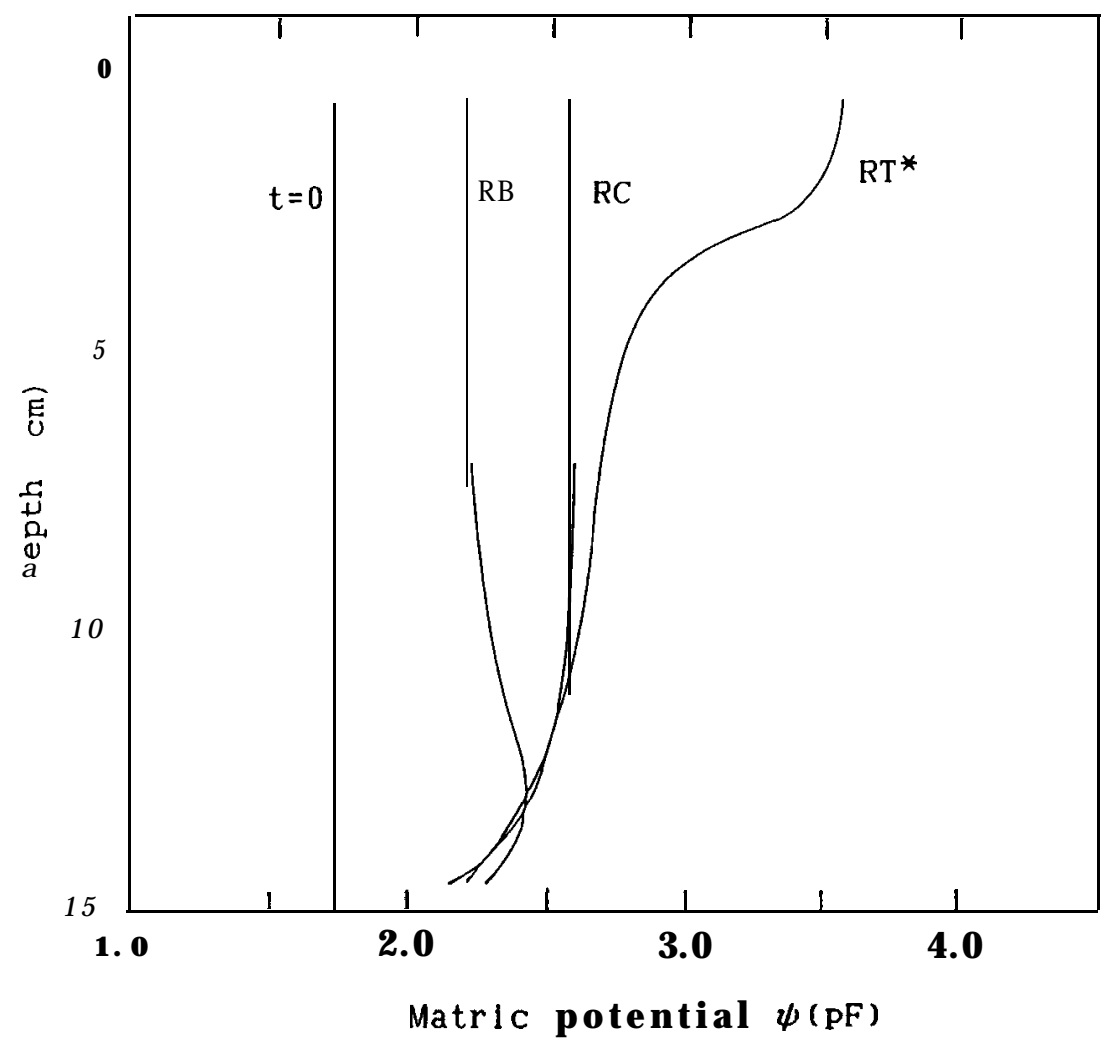

Fig. 8. Matric potential $\phi$ distribution for three types of root distribution, RT*, RC and $\mathrm{RB}$ at $t=24$ hour under daily transpiration $\mathrm{T} 2^{*}=17 \mathrm{~mm} / \mathrm{day}$, total root length per unit soil surface area $\left(\mathrm{m}^{2}\right) \mathrm{R} 2^{*}=6 \times 10^{3} \mathrm{~m}$ and conductivity of lower layer $\mathrm{C} 3^{*}=1 \times 10^{-7}$ $\mathrm{cm} / \mathrm{s}$.

\section{EXPERIMENTAL MATERIAL AND METHOD}

In general, the rate of growth of plants decreases as the soil moisture decreases. But as mentioned before, due to the spatial and temporal distribution nature of soil moisture, this relationship is not easily obtained. In irrigation the problem of soil moisture distribution is encountered in the field, and it is important to know how 


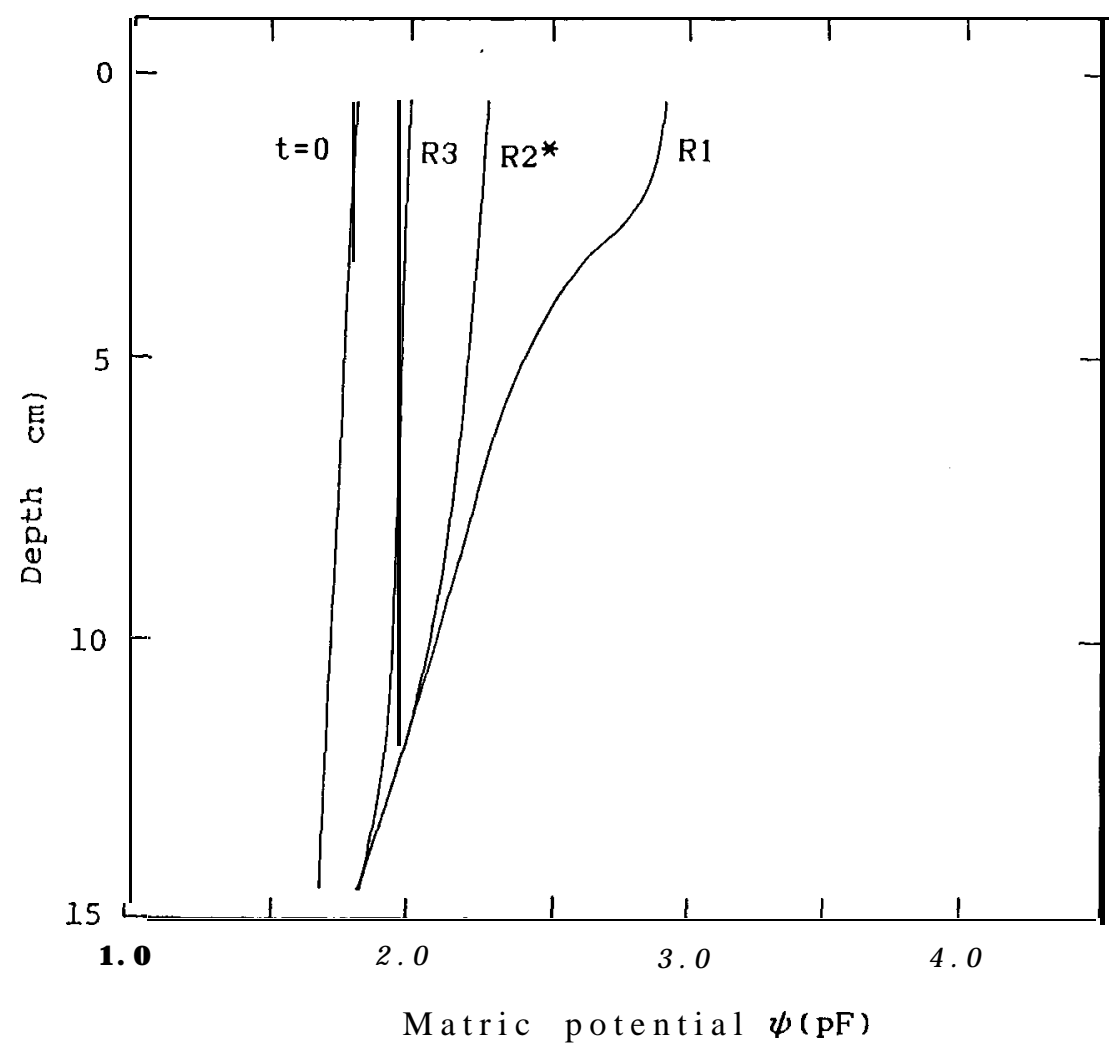

Fig. 9. Matric potential $\psi$ distribution for three total root lengths per unit soil surface area $\left(\mathrm{m}^{2}\right) \mathrm{R} 1=6 \times 10^{2} \mathrm{~m}, \mathrm{R} 2^{*}=6 \times 10^{3} \mathrm{~m}$ and $\mathrm{R} 3=6 \times 10^{4} \mathrm{~m}$ at $t=24$ hour under daily transpiration $\mathrm{T} 2^{*}=17 \mathrm{~mm} /$ day, conductivity of lower layer $\mathrm{C} 2=1 \times 10^{-6}$ $\mathrm{cm} / \mathrm{s}$ and root distribution type $\mathrm{RT}^{*}$.

distributed soil moisture status affects transpiration when irrigating the field. Evaluation of the effect of soil moisture distribution on transpiration is easy if the distributed soil moisture state can be represented by one parameter.

In this study experiment on the influence of distributed soil moisture status on transpiration was carried out under deep (distributed moisture) pot condition. Experiment under shallow pot condition (in which homogeneous moisture was assumed) was also conducted for comparison.

For the deep pot experiment, cylindrical pots (Fig. 12 (a), $415 \mathrm{~cm} \times 17 \mathrm{~cm}$ ) were packed with $15 \mathrm{~cm}$ of loamy sand soil (soil type $\mathrm{N}$ ) and were seeded to one cucumber plant (Cucumis Sativus L. var. Hort. Chojitsu-Ochiai No. 2) each. A $1 \mathrm{~cm}$ thick porous plate was placed at $17 \mathrm{~cm}$ from the rim to control soil moisture. Below the plate was a $5 \mathrm{~cm}$ tall chamber maintained at different suctions during the experiment. Porous cups were inserted at $2.5,7.5$ and $12.5 \mathrm{~cm}$ from the soil surface to measure soil moisture change to about $\mathrm{pF}$ 2.6. For higher $\mathrm{pF}$ range measurement the psychrometer (Dew 


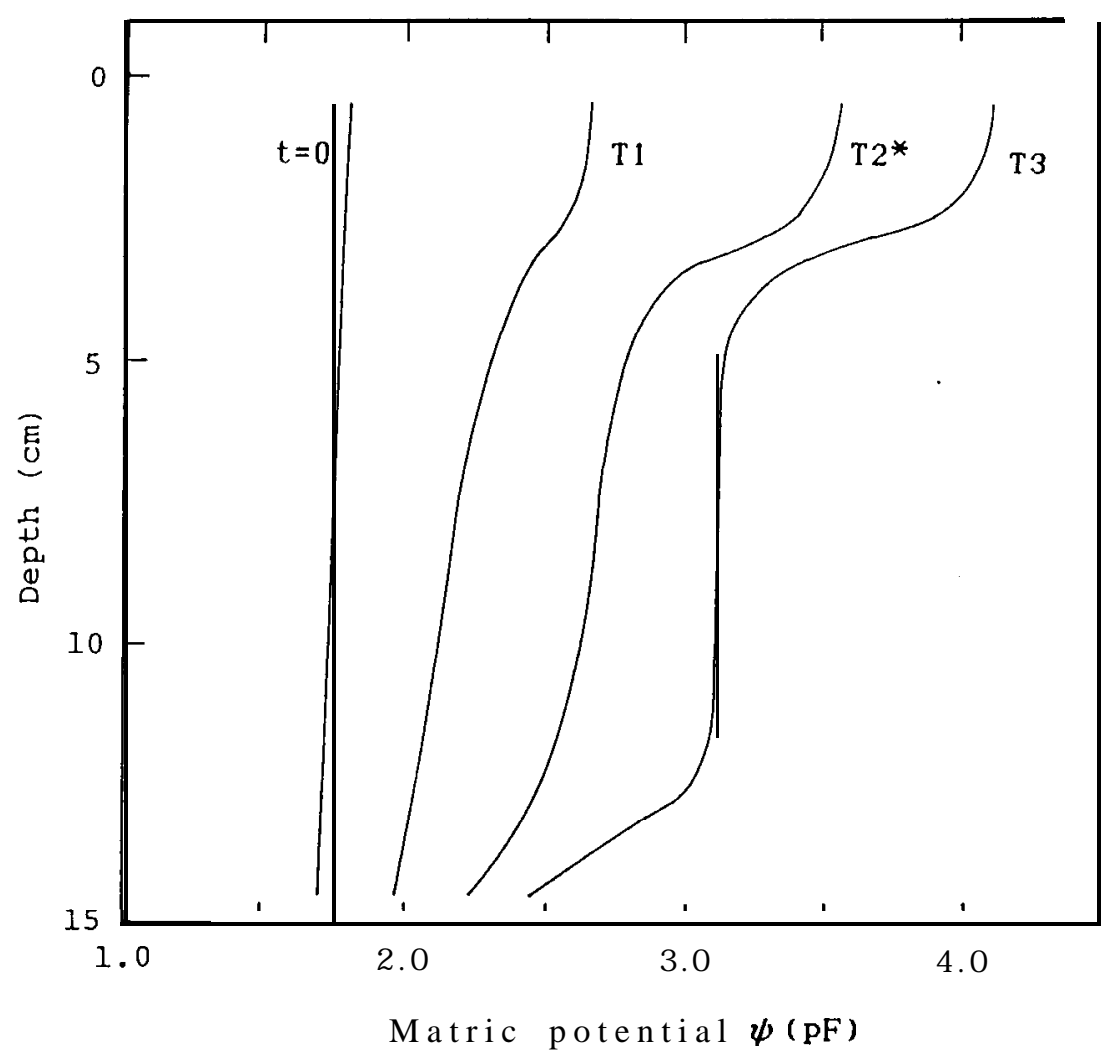

Fig. 10. Matric potential $\phi$ distribution for three daily transpirations $T 1=9 \mathrm{~mm} /$ day, $\mathrm{T}_{2}^{*}=17 \mathrm{~mm} /$ day and $\mathrm{T} 3=26 \mathrm{~mm} /$ day at $t=24$ hour under conductivity of lower layer $\mathrm{C} 3^{*}=1 \times 10^{-7} \mathrm{~cm} / \mathrm{s}$, root distribution type $\mathrm{RT}^{*}$ and total root length per unit soil surface area $\left(\mathrm{m}^{2}\right) \mathrm{R} 2^{*}=6 \times 10^{3} \mathrm{~m}$.

Point Microvoltmeter)was used.

For the shallow pot experiment, cylindrical pots (Fig. 12 (b), $\phi 15 \mathrm{~cm} \times 9 \mathrm{~cm}$ ) were packed with $7 \mathrm{~cm}$ of loamy sand soil and were seeded to one cucumber plant each. Soil moisture was found to be slightly distributed for a pot of this size, and was represented by measurement taken at $2.5 \mathrm{~cm}$ from the soil surface.

Fig. 13 gives the soil moisture characteristic (drying process) and hydraulic conductivity curves (Jackson, 1972) of loamy sand (soil type N).

The cucumber plants were cultivated in the phytotron glass room (air temperature $23 \pm 1^{\circ} \mathrm{C}$, relative humidity $70 \pm 5 \%$ ) until 5-leaf (leaf No. 1, 2 and 3 fully expanded) and 4-leaf stage (leaf No. 1 and 2 fully expanded) for the deep and shallow pot experiment, respectively. $200 \mathrm{ml}$ and $100 \mathrm{ml}$ of liquid fertilizer was added every two days after the cotyledons have fully expanded to ensure unstressed growth condition for the deep and shallow pot experiment, respectively.

For the deep pot experiment 5-leaf stage cucumber plant was transferred to the growth cabinet (air temperature $25 \pm 0.5^{\circ} \mathrm{C}$, relative humidity $40 \pm 5 \%$ and horizontal 


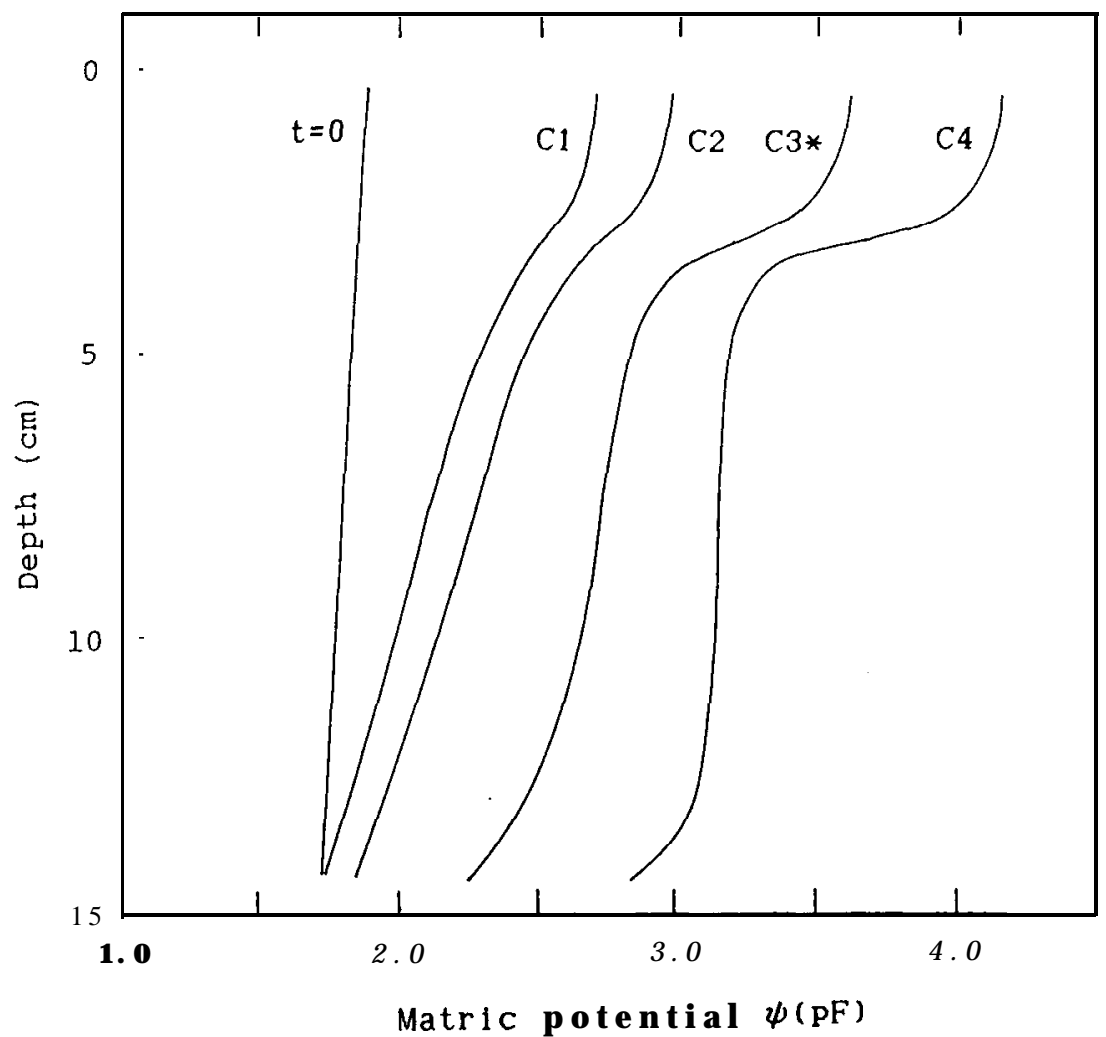

Fig. 11. Matric potential $\psi$ distribution for four conductivities of lower layer $\mathrm{Cl}=$ $1 \times 10^{-5} \mathrm{~cm} / \mathrm{s}, \mathrm{C} 2=1 \times 10^{-6} \mathrm{~cm} / \mathrm{s}, \mathrm{C} 3{ }^{*}=1 \times 10^{-7} \mathrm{~cm} / \mathrm{s}$ and $\mathrm{C} 4=1 \times 10^{-8} \mathrm{~cm} / \mathrm{s}$ at $t=24$ hour under root distribution type $\mathrm{RT}^{*}$, total root length per unit soil surface area $\left(\mathrm{m}^{2}\right) \mathrm{R} 2^{*}=$ $6 \times 10^{3} \mathrm{~m}$ and daily transpiration $\mathrm{T}^{*}=17 \mathrm{~mm} /$ day.

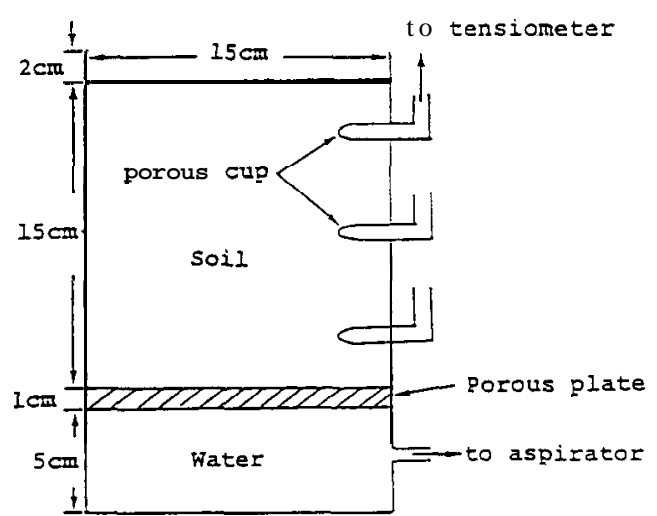

(a)

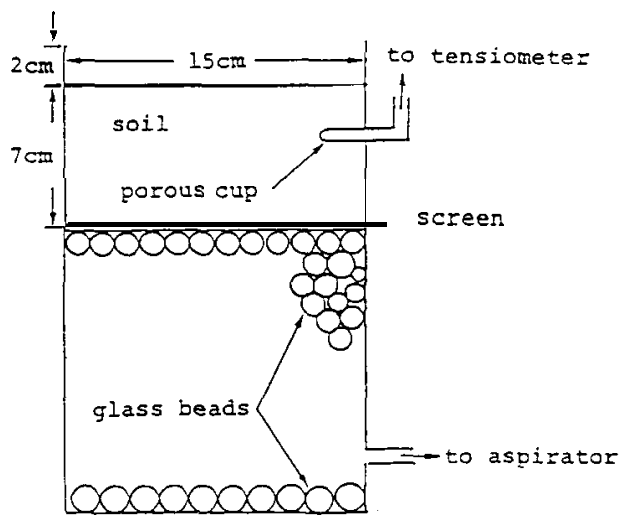

(b)

Fig. 12. Diagram of the deep pot (a) and shallow pot (b) used in the experiment 


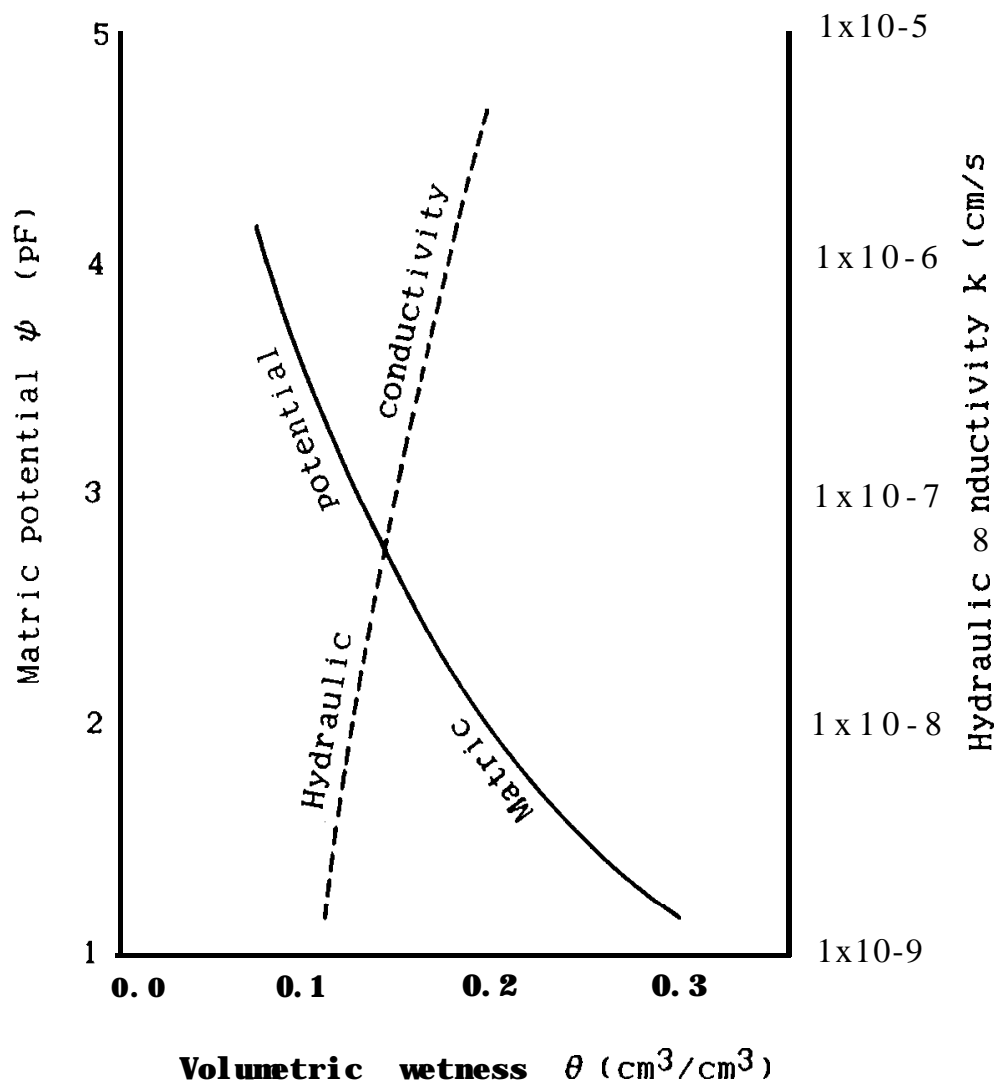

Fig. 13. Soil moisture characteristic (drying process) and hydraulic conductivity $k$ (Jackson method) for loamy sand (soil type $\mathrm{N}$ ).

wind $0.3 \pm 0.1 \mathrm{~m} / \mathrm{s}$ ) to be subjected to artificially induced transpiration by tungsten (500 W) light radiation. Initial soil moisture condition was altered to different values by applying suction through the control chamber connected to an aspirator. The plant was left in darkness for 12 hours before radiation. Soil surface was covered during the experiment to resist soil surface evaporation.

The shallow pot experiment was conducted under the same conditions and method using 4-leaf stage cucumber plant. Soil moisture was altered by applying suction at the bottom of the pot.

Transpiration rate $\left(\mathrm{gcm}^{-2} \mathrm{~min}^{-1}\right)$ was calculated by the leaf heat balance equation (Kitano et al. 1983, Koutaki et al. 1983).

\section{EXPERIMENTAL RESULTS AND DISCUSSION}

In the deep pot experiment, continuous measurement of soil moisture over a wide range of $\mathrm{pF}$ values was not possible, especially for the surface layers, due to the limited 
range of the tensiometer and psychrometer. Matric potential values not measurable by the methods were simulated by the numerical model (Hillel et al., 1976). In averaging soil moisture simulated values were used for the range not measurable. Fig. 14 shows the results of one of the simulations. The fit between the simulated curves at 7.5 and $12.5 \mathrm{~cm}$, and that of the measurement was good. It was, therefore, reasonable to approximate the data for depth $2.5 \mathrm{~cm}$ by the simulated curve of the same depth.

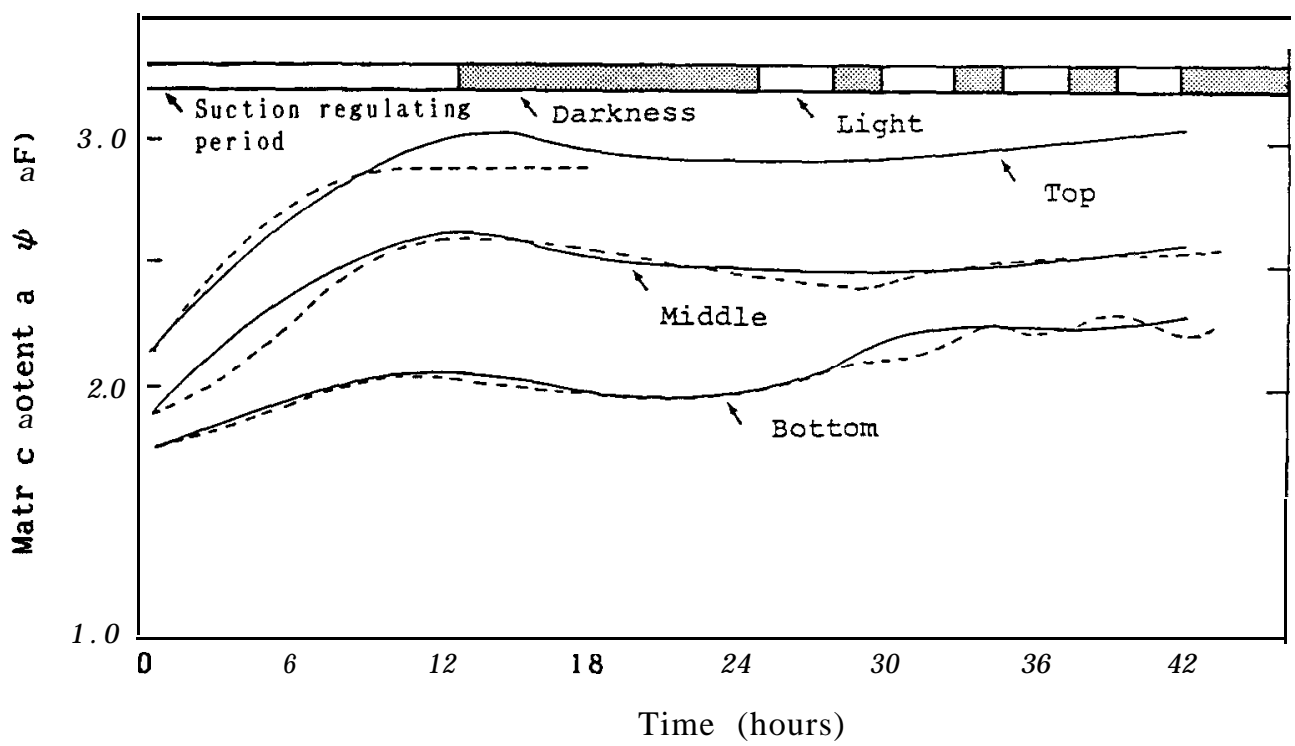

Fig. 14. Time course of simulated (solid lines) and observed (dashed lines) matric potential $\psi$ for top $(2.5 \mathrm{~cm})$, middle $(7.5 \mathrm{~cm})$ and bottom $(12.5 \mathrm{~cm})$ layer of the deep pot experiment.

To evaluate the relationship between distributed soil moisture and transpiration and to compare the results of deep and shallow pot experiment, it was necessary to evaluate the distributed conditions. For that mean integrated values of distributed soil moisture were estimated for deep pot experiment by the averaging methods of Taylor (1952), Gardner (1964), and Karamanos (1980).

Taylor (1952) estimated the mean integrated matric potential by fitting polynomial regressions to values of matric potential over time and space and by taking double integration for the time and depth considered. His approximate method for field use is

$$
T_{p, m}=\sum_{i=1}^{m} \sum_{j=1}^{n} T_{i, j} /(m \times n)
$$

where $T_{p, m}$ is the mean integrated value, $T_{i, j}$ is matric potential at time $i$ and depth $\mathrm{j}$, $m$ is the $m$ th time interval, and $\mathrm{n}$ is the $n$th depth.

In the deep pot experiment, matric potential measurements were made just before, at the middle and end of radiation. Since the readings were taken at equal time 
intervals and at depths $2.5,7.5$ and $12.5 \mathrm{~cm}$ from the soil surface, equation (13) gives an arithmetic average of soil moisture for the time and depths considered.

By considering the movement of soil water towards the roots, Gardner (1964) used a theoretical approach to estimate an integrated matric potential

$$
\tau=\left[\sum k_{i} \times r_{i} \times\left(\tau_{i}+z_{i}\right)\right] / \sum k_{i} \times r_{i}
$$

in which $\tau$ is the mean integrated value, $\tau_{2}$ is matric potential, $k_{2}$ is hydraulic conductivity and $r_{i}$ is root distribution, at depth $z_{i}$, respectively.

In equation (14) matric potential is weighted by root distribution and hydraulic conductivity at the depths considered. Likewise, three hydraulic conductivities and root distributions at the depths of measurement were taken as the weighting factors for the observed soil moisture data.

Karamanos (1980), by using the rate of soil water depletion of different layers at the time of measurement as the weighting factor, calculated the average soil matric potential at a given time

$$
\phi_{m, s}=\left[\sum_{z=1}^{n}(\Delta \theta / \Delta t)_{z} \times \phi_{m, s, z}\right] / \sum_{z=1}^{n}(\Delta \theta / \Delta t)_{z}
$$

wherein $\phi_{m, s}$ is mean integrated value, $\phi_{m, s, z}$ is matric potential, and $(\Delta \theta / \Delta t)_{z}$ is water depletion, at depth $z$, respectively.

In the experiment, soil moisture depletion of the depths of measurement was taken as the difference between the moisture at start and end of each radiation. The weighting factor was multiplied by matric potential at the middle of each radiation to give the mean integrated matric potential.

Fig. 15 gives the relationship between transpiration rate and mean integrated matric potential calculated by Taylor's (1952) method for four moisture regimes Ml, M2, M3 and M4. The number in the figure shows the sequence of radiation for each regime. For high moisture content (regime Ml) transpiration rate was observed to decrease drastically with subsequent radiations. This trend was not observed for low moisture regime. One explanation was that, for regime $\mathrm{Ml}$ transpiration rate was not balanced by root uptake after the first radiation, i. e., root absorption of water temporarily lagged behind transpiration rate. Also, root extraction during the radiations could be excessively large that soil in the vicinity of roots was drier than that shown by the measured values. Since the first radiation of the experiment was conducted after 12 hours of darkness, only the first radiation of each moisture regime was considered in evaluating the relationship between transpiration rate and distributed soil moisture.

Fig. 16 gives the relationship between transpiration rate of the first radiation and mean integrated matric potentials obtained by the averaging method of Taylor (1952), Gardner (1964) and Karamanos (1980). The agreement among the mean integrated potentials obtained by the three methods was good. The results of the shallow pot experiment were included in the figure. The relationship between relative transpiration rate and mean integrated potentials by the three methods were in good agreement with each other, and the agreement with that of the shallow pot experiment was fairly good, showing that for a distributed soil moisture system the relationship between transpiration and soil moisture can be effectively evaluated by a mean integrated 


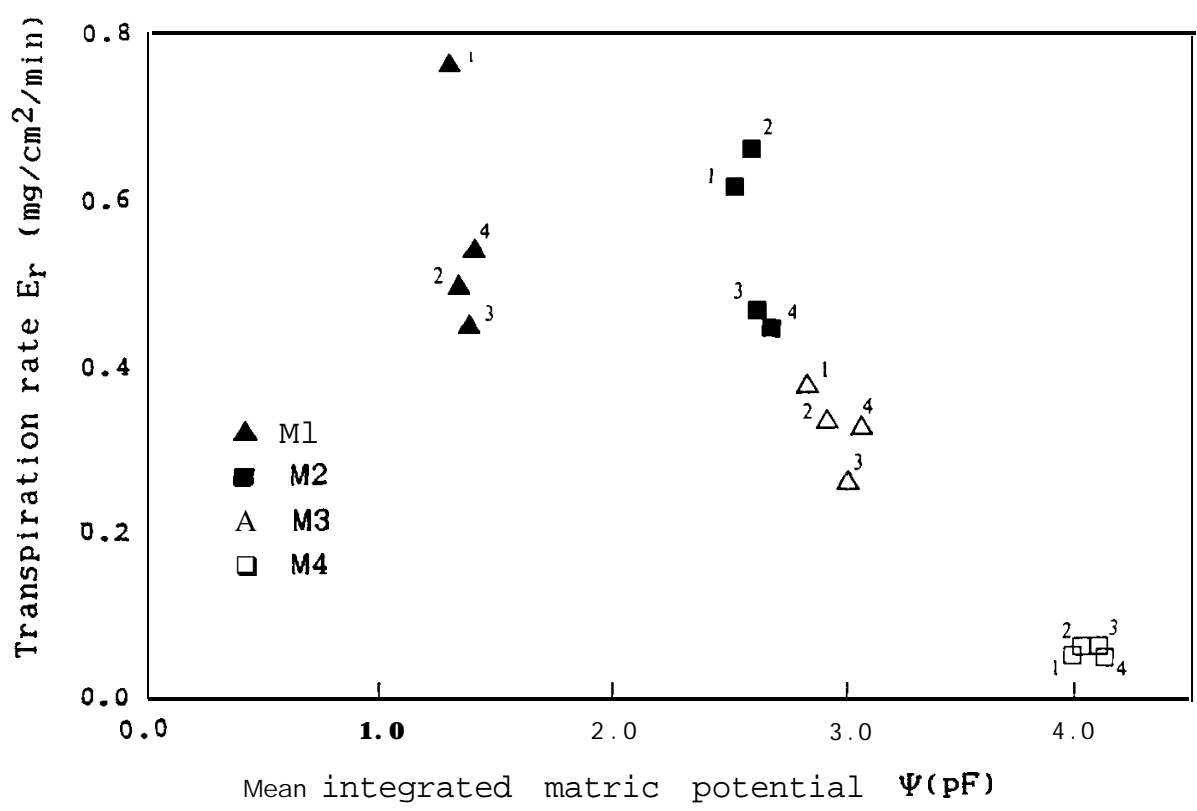

Fig. 15. Relationship between transpiration rate $E_{3}$ and mean integrated matric potential $\Psi$ calculated by Taylor's method for four soil moisture regimes Ml, M2, M3 and M4. The numbers show the sequence of radiation of each moisture regime.

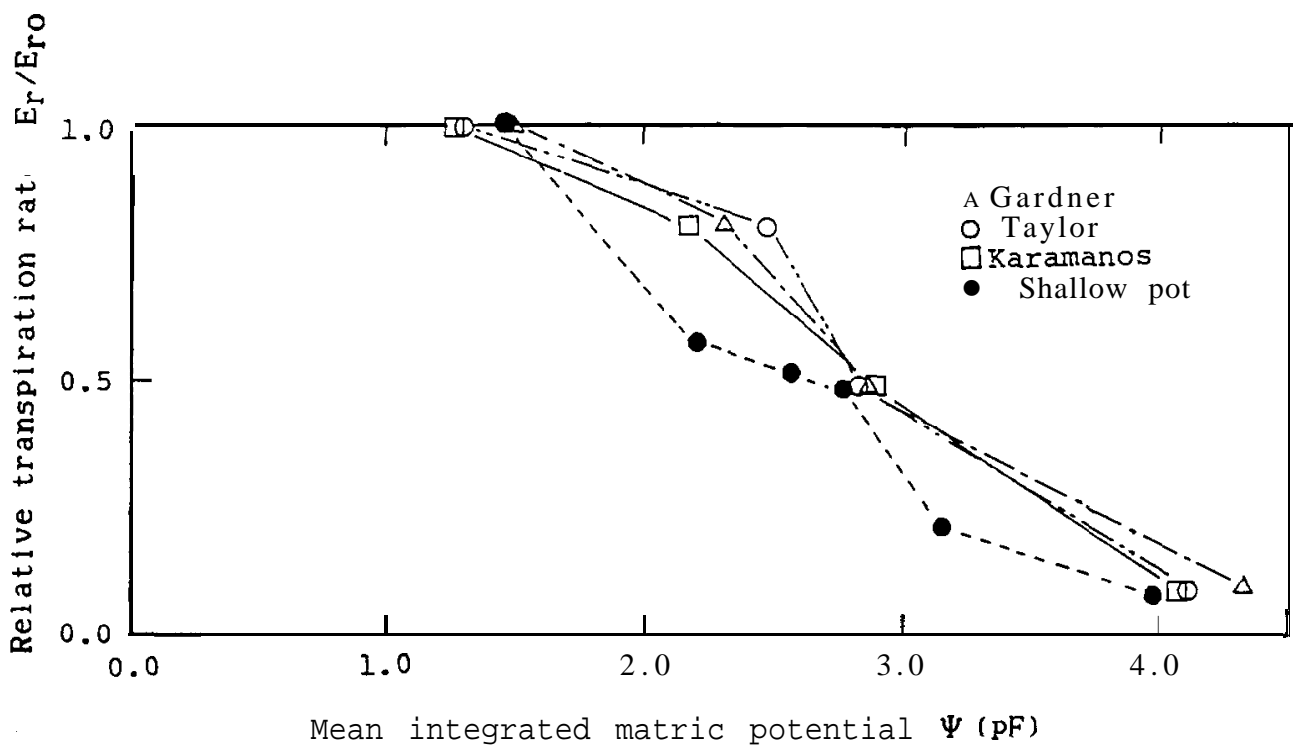

Fig. 16. Relationship between relative transpiration rate $E_{r} / E_{r}$ and three types of mean integrated matric potential $\Psi$ of the deep pot experiment calculated by Gardner, Taylor and Karamanos' method $: E$, transpiration rate $; E_{r o}$, maximum transpiration rate. The curve of the shallow pot experiment is plotted for comparison. 
value. All curves indicated decreasing transpiration rate with decreasing matric potential and at $\mathrm{pF}$ value greater than 4 transpiration rate was very low. This trend was similar to that reported by Bahrani and Taylor (1961) that the ratio of actual to potential evapotranspiration decreased curvilinearly with soil matric potential with most of the reduction taking place at low potential.

Taylor's (1952) method gives a simple procedure of estimating mean integrated potential by taking the average of potential over space and time, but the extent of the soil depth that should be considered is not easily obtained. Gardner's (1964) method uses root distribution and hydraulic conductivity as the weighting factors, but the data of these two factors are difficult to obtain accurately in situ. Karamanos' (1980) method uses soil water depletion of the layers at the time of measurement as the weighting factor. This data is easily obtained from soil moisture observation in the field. Therefore, from the practical viewpoint Karamanos' (1980) method is a useful method.

\section{CONCLUSION}

The simulation results of soil moisture distribution as affected by soil, crop and environmental factors showed that moisture distribution was large for 1) soil with small hydraulic conductivity index $(K), 2)$ the state of root distribution under favorable moisture condition, 3) small total root length per unit soil surface area, 4) large daily transpiration, and 5) small conductivity of the lower layers. For soil with the same $K$ but large water retentivity index $(\Theta)$, distribution was small over short period of time. In soil with large response index $(r)$, distribution was small after attainment of steady state. Therefore, a relatively uniform soil moisture profile over space and time, such as that in the experimental pot, can be achieved by 1) using soil with large $K$ and $Y$ together with a porous plate of large conductivity, 2) keeping root distribution as uniform as possible, and 3) increasing total root length per unit soil surface area. However, crop and environmental factors are difficult to control.

The results of deep and shallow pot experiment showed that transpiration rate decreased with decreased in matric potential. Mean integrated matric potentials for the deep pot experiment by the methods of Taylor (1952), Gardner (1964), and Karamanos (1980) were in good agreement with each other. The relationship between relative transpiration rate and mean integrated potentials by the three methods agreed fairly well with that of the shallow pot experiment. The results of the experiment demonstrated that for a distributed soil moisture system the relationship between transpiration and soil moisture can be effectively evaluated by mean integrated values such as that obtained by the averaging methods used hereinbefore.

\section{ACKNOWLEDGEMENTS}

The authors wish to express their deep gratitudes to Professor Dr. H. Eguchi (Biotron Institute, Kyushu University) for his advice, encouragement and use of the facilities of the Institute, to Mr. M. Koutaki, then a graduate student of the Institute, for assisting and cooperating in the experiment, to Mr. T. Funakoshi (Lab. of Irrigation and Water Utilization, Kyushu University) for his technical support. 
This work was supported by the Grant-in-Aid for Scientific Research (A), Ministry of Education, Japan.

\section{REFERENCES}

Bahrani, B. and S. A. Taylor 1961 Influence of soil moisture potential and evaporative demand on actual evapotranspiration from alfalfa field. Agronomy J., $53:$ 233-237

Gardner, W. R. 1964 Relation of root distribution to water uptake and availability. Agronomy $J$., 56: $41-45$

Hillel, D., H. Talpaz and H. van Keulen 1976 A macroscopic-scale model of water uptake by a nonuniform root system and of water and salt movement in the soil profile. Soil Sci., 121 (4) : 242 $\mathbf{- 2 5 5}$

Jackson, R. D. 1972 On the calculation of hydraulic conductivity. Soil Sci.Soc. Amer. Proc., 36 : 380-382

Karamanos, A. J. 1980 Response in plant water status to integrated values of soil matric potential calculated from soil water depletion by a field bean crop. Aust. J. Plant Physiol., 7: 51-66

Kitano, M., H. Eguchi and T. Matsui 1983 Analysis of heat balance of leaf with reference to stomata1 responses to environmental factors. Biotronics $12: 19-27$

Koutaki, M., H. Eguchi and T. Matsui 1983 Evaluation of stomatal activity by measuring leaf temperature dynamics. Biotronics $12: \mathbf{2 9 - 4 2}$

Nye, P. H. and P. B. Tinker 1977 Solute movement in the soil-root system. University of California Press: 252

Redmann, R. E. 1976 Plant-water relationships in a mixed grassland. Oecologia 23 : 283-295

Taylor, S. A. 1952 Estimating the integrated soil moisture tension in the root zone of growing crops. Soil Sci., 73 (5) :331-339

Taylor, H. M. and B. Klepper 1975 Water uptake by cotton root system: an examination of assumptions in the single root model. Soil Sci, 120 (1) : 57-67

Wadleigh, C. H. 1946 Integrated soil moisture stress upon a root system in a large container of saline soil. Soil Sci., $61: 225-238$ 